\title{
Entre infraestructuras y culturas. Discursos y prácticas en torno a la movilidad urbana en Andalucía
}

\author{
Between infrastructures and cultures. Discourses and \\ practices around urban mobility in Andalusia
}

\author{
Macarena Hernández-Ramírez y Mario Jordi Sánchez² \\ Fecha de recepción: 22-01-2020 - Fecha de aceptación: 16-06-2020 \\ Hábitat y Sociedad (ISSN 2173-125X), n. . 13, noviembre de 2020, pp. 11-28. \\ http://dx.doi.org/10.12795/HabitatySociedad.2020.i13.02
}

\begin{abstract}
Usually, the figures and facts used to analyze cycling mobility in the urban environment, are hardly based in references to infrastructures as a factor that facilitates / hinders that mobility. Convinced of the need to consider other influential variables, we address from the CICLA project the general objective of knowing mobility in urban areas of Andalusia. More specifically we are committed to knowing which are the main social discourses and practices around the use of the bicycle, within the need to incorporate social, economic, political and cultural aspects usually separated from the analysis. Based on a qualitative methodology and a holistic approach, the results of this research shed light on some of these aspects, providing some conclusions and reflections of interest for the promotion of the bicycle as a means of transport in our cities.
\end{abstract}

Key words

Culture; Infrastucture; Social use; Bicycle; City

\begin{abstract}
Resumen
De forma habitual, las cifras y hechos que se emplean para analizar la movilidad ciclista en el ámbito urbano están fuertemente basadas en las infraestructuras como factor que facilitan/dificultan esa movilidad. Con el convencimiento de la necesidad de considerar otras variables influyentes, abordamos desde el proyecto CICLA el objetivo general de conocer la movilidad en zonas urbanas de Andalucía. Más concretamente, apostamos por estudiar los principales discursos y prácticas sociales en torno al uso de la bicicleta, dentro de la necesidad de incorporar aspectos sociales, económicos, políticos y culturales habitualmente apartados del análisis. Con una metodología de corte cualitativo y un enfoque holístico, los resultados de esta investigación arrojan luz sobre algunos de estos aspectos, aportando algunas conclusiones y reflexiones de interés para la promoción de la bicicleta como medio de transporte en nuestras ciudades.
\end{abstract}

Palabras clave

Cultura; Infraestructura; Uso social; Bicicleta; Ciudad

1 Profesora de la Universidad Pablo de Olavide, Sevilla, España. E-mail: mherram@upo.es. ORCID: 0000-0003-0793-3746

2 Profesor de la Universidad Pablo de Olavide, Sevilla, España. E-mail: amjordi@upo.es. ORCID : 0000-0003-3115-8540 


\section{Introducción}

El hábitat por excelencia del ser humano en el siglo xxi ha pasado a ser la ciudad (Barrios, 2012). El Fondo de Población de las Naciones Unidas calcula que fue en 2008 cuando más de la mitad de la población mundial pasó a ser urbana. Se computa además que la población mundial llegó a los siete mil millones de personas en octubre de 2011, (UNFPA y Bárbara, 2011) y que, en 2050, pueda oscilar entre nueve mil y dieciséis mil millones de habitantes, en función de las políticas sobre control de la población que se lleven a cabo (DESA, 2011; Herrmann, Guzmán y Schensul, 2012). Por otra parte, las estimaciones sobre el crecimiento urbano prevén que para el año 2030 cinco mil millones de personas vivirán en ciudades y que siete de cada diez urbanitas vivirán en África o Asia (UNFPA y Bárbara, 2011; UNFPA, 2007). En España el porcentaje de personas que vive en ciudades $(80 \%)$ supera la media europea $(75 \%)$, concentrándose sobre todo en el centro y el litoral peninsular (Barrios, 2012; UNFPA, 2007).

El transporte motorizado es el actual protagonista en los patrones de movilidad de esta población crecientemente concentrada en las urbes. Este protagonismo del transporte motorizado, y especialmente, del automóvil, ha dejado escaso lugar a otros medios alternativos, como la bicicleta (Paterson, 2007). La historia del uso social de este objeto ha experimentado fluctuaciones, a lo largo de su breve historia, de forma análoga a otros países de nuestro entorno (Augé, 2009): de vehículo utilitario de cierta distinción social en sus etapas originarias, pasó a ser un transporte de sectores trabajadores en las primeras décadas del siglo $\mathrm{xx}$, hasta ir paulatinamente desapareciendo de nuestras calles, en beneficio del automóvil privado. Del mismo modo, los peatones han visto también limitada su movilidad, la cual ha sido progresivamente objeto de reglamentaciones y ordenamiento público, en aras a su progresivo constreñimiento en la ciudad.

Como resultas de todo ello, la bicicleta ha visto minorada su presencia en el tránsito viario y en el espacio físico al mismo tiempo que ha reducido su prestigio en el espacio simbólico social, pasando a ser una forma de movilidad tan residual como menospreciada (Urry, 2007). Solo el ciclismo deportivo y algunas formas de ciclismo recreativo han permanecido al margen de este proceso de devaluación. El transporte en bicicleta resiste el empuje del tráfico motorizado privado solo en ciertos sectores sociales, muy notablemente en el ámbito rural, como comprobamos en Andalucía, donde en algunos municipios y comarcas podemos constatar su uso ininterrumpido a pesar de las tendencias de motorización general de la sociedad (Hernández, 2016). En fechas recientes, se produce un leve resurgir del ciclismo en algunas ciudades andaluzas por parte de sectores jóvenes urbanos, generalmente de cierto nivel educativo, y con frecuencia asociado a estilos de vida alternativos o disidentes y a la por entonces incipiente sensibilización social por los problemas medioambientales. En las últimas décadas del siglo $\mathrm{xx}$, al calor de esta actividad con connotaciones de disidencia social, nacen en Andalucía, como en otros territorios de nuestro entorno, las primeras asociaciones en defensa de los derechos de los ciclistas urbanos (Río y Coca, 2017). Este tímido resurgir es un claro antecedente del actual incremento del ciclismo urbano como transporte en expansión y cuya proyección inmediata muestra signos muy prometedores. Entre los objetivos y reclamos tanto de estos grupos, como de las y los usuarios, destaca la reivindicación de infraestructuras propias para las 
bicicletas dentro de las ciudades (Martín y Gálvez, 2016). A partir de este momento entra en agenda (tanto de planificadores como de usuarios/as) los espacios ciclistas como parte de la movilidad en el contexto urbano. La existencia o no, el volumen, el estado y uso de esta infraestructura ciclista en nuestras ciudades, se convierte en indicador de uso, en evidencia de la gestión política y en una eterna disputa entre las y los usuarios que la reclaman y los que no.

La continuidad del uso de la bicicleta, con estas fluctuaciones en su devenir histórico, evidencia las ventajas que presenta como modo de transporte urbano y metropolitano, no solo desde el punto de vista de la lucha contra el cambio climático, sino también desde los puntos de vista del uso eficiente de la energía y del espacio urbano, así como de la mejora de la salud pública (Garrard, Rissel, y Bauman, 2012). No es pues de extrañar el creciente interés en su promoción y el renacimiento que dicho modo está experimentando en todo el mundo (Pucher y Buehler, 2012). Forman parte de este proceso tanto los usos tradicionales de la bicicleta, como otros usos de más reciente aparición, como las grandes infraestructuras de intermodalidad con el transporte público (ob. cit.), las bicicletas públicas (De Maio, 2009; Larsen y El-Geneidy, 2009; Lin y Yang, 2011; Parkin, 2012; Willis, Paige, Manaugh y El-Geneidy, 2015), los pedelecs o bicicletas eléctricas (Pucher y Buehler, 2012), la ciclo-logística o uso de la bicicleta para realizar transportes de última milla (Reiter y Wrighton, 2014), el cicloturismo como fenómeno de masas, etc.

Las políticas y procesos sociales asociados a la promoción de la bicicleta en el marco de la movilidad urbana se desarrollan a todas las escalas, internacional, nacional y local, si bien, por su naturaleza urbana, presentan en la mayoría de las ocasiones un ámbito de actuación local. Ello da lugar a una amplia variedad de políticas y procesos, de muy diversos modos de proceder y resultados (Pucher y Buehler, 2012; ConBici, 2007), entre los que no podemos dejar de contemplar cómo las infraestructuras ciclistas ostentan un papel destacado.

Obtener un entorno seguro para la movilidad ciclista, ya sea mediante la creación de redes de vías ciclistas o mediante el calmado del tráfico (o ambos), resulta esencial en el marco de aquellas políticas, no conociéndose en nuestro entorno casos de ciudades que hayan alcanzado niveles significativos de participación de la bicicleta en la movilidad urbana sin haber desarrollado simultáneamente tales iniciativas (Pucher y Buehler, 2012; ConBici, 2007). No obstante, la creación de vías ciclistas no garantiza por si sola un incremento significativo del ciclismo urbano. Se conocen casos de ciudades que han intentado desarrollar dichas políticas sin éxito (ConBici, 2007). Igualmente ocurre con los sistemas de bicicletas públicas (Anaya y Castro, 2012; Castro, 2015). Todo ello evidencia que el éxito en las políticas de promoción de la bicicleta depende de factores que van mas allá de la mera construcción de infraestructuras. La proximidad entre usos y funciones urbanas en el espacio, la cual se ha denominado como "compacidad", se presenta como otro de los elementos que, más allá de la existencia o no de infraestructuras ciclistas, pueden determinar el éxito en la implementación de estas políticas (Rueda, 1996). Influyen igualmente sin duda los procesos sociales que favorecen o retrasan la integración de la bicicleta en la movilidad urbana (Horton, Rosen y Cox, 2007) y que abarcan desde las percepciones acerca de la seguridad y del riesgo, a las constricciones impuestas por familias y estilos de vida, pasando por la influencia de la cultura y la 
imagen, o el impacto del clima y la orografía, entre otros (Cox, 2015). Por todo ello, emerge como una necesidad implementar análisis relacionados con los elementos socioculturales que influyen, condicionan o determinan el devenir de este tipo de intervenciones. Aspirar a una normalización de la población ciclista, superando las constricciones subculturales que limitan los usos a sujetos y colectivos específicos sería uno de los principales retos a afrontar para posteriormente desarrollar cualquier diseño de intervención planificadora con vocación democrática e integradora (Parkin, 2012).

\section{Caso de estudio: métodos y miradas}

Los datos y aportaciones incluidos en el presente texto son resultados del proyecto Movilidad sostenible en Andalucía: prácticas y discursos en el uso de la bicicleta ${ }^{1}$ cuyos objetivos fundamentales se centraron en analizar y registrar los diferentes usos y prácticas relativas a la movilidad sostenible en general, y al ciclismo utilitario en particular, en los espacios urbanos de Andalucía, de cara a poder elaborar recomendaciones para el fomento del uso de la bicicleta en Andalucía.

En este proyecto ha trabajado un equipo de 14 investigadores, de diferentes procedencias, trayectorias y disciplinas: antropología, sociología, psicología, ambientales, arquitectura, etc., lo que sin duda ha permitido una interdisciplinariedad que ha contribuido de forma decisiva a trabajar desde la mirada global que requiere el fenómeno del ciclismo urbano. Desde la aplicación de la técnica de la observación participante, estos investigadores de ambos sexos han aportado el análisis de discursos y prácticas de una gran cantidad de sujetos en diferentes entornos urbanos, así como su experiencia directa de movilidad, en sus diversas formas: como ciclistas, peatones, usuarios/as de transporte público o conductores.

Para comprobar nuestros objetivos e hipótesis para este proyecto se ha optado por la composición de un estudio de caso por cada una de las zonas estudiadas: Cádiz, Córdoba, Granada, Málaga, Sevilla, Huelva y Almería, combinando diferentes metodologías:

En primer lugar, de manera destacada y en concordancia con los objetivos planteados, se ha desarrollado como estrategia principal en cada zona, una etnografía de corte antropológico; ello permitió demarcar y dimensionar cada una de las variables en su contexto específico. La etnografía, como modelo de estudio cualitativo, ha comportado el trabajo desde dentro de cada territorio elegido, con estancias de las investigadoras/es que se han prolongado 15 meses en cada caso. La referida observación participante ha sido la técnica más implementada, complementada con otras técnicas desarrolladas en paralelo: entrevistas (formales e informales, abiertas y semidirigidas).

El protagonismo de la etnografía anima también a la utilización de estrategias de carácter grupal y participativo, tales como los foros de participación. En estos se han reunido a personas diversas (con criterio representativo, situacional, reputacional) para detectar problemas, lograr consensos (o en su caso detectar áreas de disensos) y establecer acuerdos y propuestas. Para la celebración de estos foros se ha realizado en cada zona de estudio un previo e intenso trabajo de campo, dirigido a localizar y contactar participantes, y a definir de un prediagnóstico con el que trabajar. Se celebraron un total de 14 foros entre todas las zonas de estudio. Los temas tratados en estos foros participa-

1 Subvencionado por la consejería d Fomento y Vivienda de la Junta de Andalucía dentro de la convocatoria $\mathrm{I}+\mathrm{D}+\mathrm{i}$ de 2013/201). Proyecto realizado desde noviembre de 2013 hasta septiembre de 2015. www.proyectocicla.org. 
tivos variaron en cada uno de los contextos analizados, pues surgieron a partir de las iniciativas de los propios grupos, los cuales planteaban sus propuestas temáticas y problemáticas de interés. El trabajo de las y los investigadores se centró en coordinar y moderar dichas sesiones con la mínima injerencia posible, orientando el discurso hacia el registro de consensos y disensos en torno al uso de la bicicleta en la ciudad, así como las posibles respuestas y estrategias ante los problemas planteados.

Todo ello se ha combinado con la celebración durante las primeras fases de la investigación de un total de 12 grupos de discusión para el registro y análisis de discursos sociales en torno a la bicicleta. Se reunieron de manera representativa (obreros/as, estudiantes, amas de casa, funcionarios/as, etc.) en grupos de entre 5 y 10 participante, con un perfil definido según variables socioeconómicas, género, etc. El resultado de estos grupos de discusión fue uno de los principales insumos recabados en el comienzo del trabajo de campo. Todo ello junto al análisis de documentación y fuentes secundarias permitió encarar con garantías la campaña de trabajo de campo en cada sistema metropolitano andaluz elegido.

Una vez concluidas cada una de estas metodologías, se procedió a triangular la información, de sistematizar y establecer correlaciones (Figura 1). De especial interés científico ha resultado el modo en que se ha resuelto esta última fase de elaboración de resultados y redacción, aplicando todo un sistema de trabajo y de intercambio de información (entre las diferentes zonas e investigadores) que posibilitó dar respuesta al objetivo de reflexionar por ejes temáticos (después de la contextualización por áreas) y sobre todo de acertar en las propuestas de intervención que se propusieron.

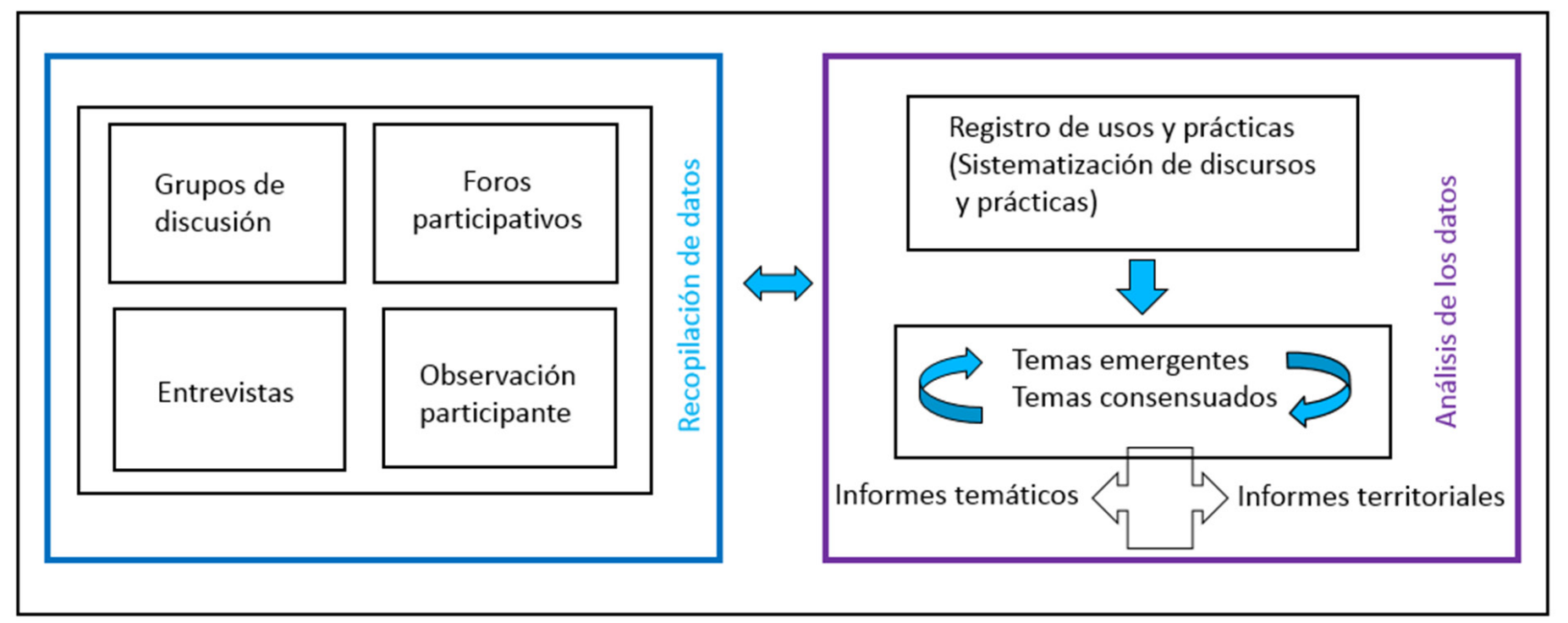

El análisis de la información obtenida siguió un esquema iterativo dentro del paradigma de la Metodología de la Teoría Fundamentada (Strauss y Corbin, 2002). Un primer procesamiento de los datos obtenidos por los cuatro grupos de técnicas aplicadas (entrevistas, observación participante, grupos de discusión y foros participativos) estableció su conexión con los objetivos preliminares de la investigación, centrado en el registro y catalogación de los principales usos u prácticas ciclistas. Este primer procesamiento, centrado en un análisis de contenido
Figura 1. Representación gráfica sintética del proceso de recopilación y análisis de datos. Fuente: proyecto CICLA, elaboración propia. 
(Hsieh y Shannon, 2005) llevó a la emergencia de nuevos ejes temáticos, como los relacionados con el género, la salud, la sociabilidad, o el papel de las infraestructuras, que fueron enriquecidos en sucesivas fases de recopilación de datos, elaborando temas consensuados. La aparición de estos temas emergentes fue producto, como decimos, de un complejo proceso de intercambio y puesta en común de la información dentro del grupo, y concluyeron en una serie de temas consensuados, de mayor complejidad. Este proceso cristalizó, finalmente, en la elaboración de informes temáticos para cada uno de ellos, que se complementaron con informes territoriales para cada una de las áreas temáticas de estudio.

\section{Resultados}

\section{Caminos hacia una nueva normalización}

La primera evidencia que surge a partir del trabajo de investigación apunta a un aumento generalizado del uso de la bicicleta en todas las zonas estudiadas. Este aumento se observa de modo gradual y, lo que es más importante, apunta a un proceso de paulatina normalización. Es decir, está cambiando el modo en que se representa a la bicicleta, cada vez más se percibe como una herramienta de movilidad, aún minoritaria, sujeta a modas, pero progresivamente utilizable por públicos muy diversos.

Aunque en algunos entornos aún se concibe a la bicicleta como objeto de ocio o deporte, o limitado a un perfil exclusivo, los discursos recopilados de diversos agentes sociales apuntan a un cierto cambio de mentalidad, con una menor presencia de estereotipos. Emerge la constatación de nuevas estéticas asociadas a la bicicleta, como expresan los siguientes testimonios:

Toda esta moda de las bicis chic tiene algunos aspectos positivos. Entre ellos está que están ayudando a cambiar la mentalidad, todavía muy instalada, de que la bici es cosa de aventureros locos o de deportistas horteras vestidos con licra... Creo que estas cosas muestran que puedes ir en bici y vestir bien o normal, e incluso tener estilo, y eso ayuda a normalizar el uso de la bici (empresario de la bicicleta, Málaga).

Tú vas a cualquier ciudad donde se ha normalizado la bicicleta y van los ejecutivos en bicicleta y en Sevilla ya se ven los profesores con su chaqueta y su corbata montando en bicicleta a clase, ¿no? (representante político, Sevilla).

Esta paulatina integración de la bicicleta como transporte contrasta con la imagen de hace una década, cuando el uso de la bicicleta estaba estigmatizado y los ciclistas o bien eran una minoría diferenciada del resto de la población, gente de escasos recursos sin dinero suficiente para tener una moto o un coche, o eran hippies o ciudadanos de tendencia ecologista. Esta imagen está cambiando, y en ello, sin duda, también ha influido la moda de la bicicleta; la bicicleta como medio de transporte en la ciudad se va convirtiendo en un objeto de consumo positivamente connotado. Todo ello, entendemos, ha contribuido a diluir aquellas imágenes de la bicicleta y de quienes la usaban, generando a su vez, nuevos significados. Entre los remanentes que en nues- 
tro ámbito de estudio encontramos de estos estereotipos se encuentran algunas prácticas y discursos que pueden agruparse en los siguientes frentes:

- La forma de circular, a veces distraída, a veces errante e incluso con formas de competitividad "deportiva" en los desplazamientos más "obligados".

- La asociación discursiva de la práctica ciclista con el ejercicio físico, la destreza y la habilidad, aptitudes que resultan a veces masculinizadas.

- Las reticencias a usar la bicicleta por sus influencias "inevitables" en la imagen, ya sea por la vestimenta que se supone "adecuada", como por otros inconvenientes como el sudor.

De este modo, esta progresiva normalización, presenta diferentes velocidades en el caso andaluz. Podría hablarse de la existencia de una doble realidad en Andalucía a nivel de fomento y uso de la bicicleta como medio de transporte, encarnada por una parte por el caso sevillano, y por otra por el resto de ciudades andaluzas. La capital sevillana destaca claramente en la presencia de bicicletas en el espacio y en la movilidad urbana; el uso de la bicicleta en Sevilla constituye un caso sin precedentes. En apenas unos años, esta ciudad se ha visto transformada por la aparición de una masa ciclista que ha desencadenado una serie de procesos socioculturales, económicos y políticos, que aún siguen en marcha y cuyo potencial apenas comenzamos a vislumbrar, pero que sin duda alguna puede ofrecer un buen punto de referencia. Por su parte Córdoba, Málaga, Granada y Cádiz viven un proceso de cambio alentador, y Almería y Huelva permanecen rezagadas, pero no frenadas en el despegue.

La experiencia del fomento de la bicicleta en Sevilla presenta, por tanto, una serie de singularidades destacadas. Unos 24 millones de desplazamientos en 2011, que constituyen un 9\% de los desplazamientos mecanizados, situaron a esta ciudad en la posición de liderazgo en la movilidad ciclista no solo en Andalucía, sino en toda España. El dato cobra mayor relevancia si se compara con el mismo porcentaje de 2006, año de partida en las nuevas infraestructuras y políticas de fomento de la bicicleta. Por entonces la bicicleta como vehículo suponía solamente el 0,6\% del reparto modal (Marqués, Hernández-Herrador, Calvo-Salazar y García-Cebrián, 2015). Este enorme incremento en un plazo de tiempo tan corto supuso un hito sin precedentes que ha tenido una enorme repercusión de alcance internacional, que se ha reflejado no solo en la prensa especializada - como los boletines de la European Cyclists' Federation o la revista californiana Bicycle Retailer, por poner solo dos ejemplos- sino también por parte de medios de comunicación como la BBC o publicaciones sobre turismo líderes del sector con difusión mundial, tales como Lonely Planet.

Pero, por encima de estos hechos, como decimos, se hace patente una progresiva presencia de diferentes perfiles de ciclistas, desmontando progresivamente barreras de género, edad, clase social e ideológicas, entre otras. Entre los factores que explican esta diversificación se encuentran, con diferentes pesos en distintos contextos, la expansión de la conciencia ecologista y medioambiental; una mayor preocupación por la incorporación de hábitos saludables y deportivos; las consecuencias de la crisis económica y la pérdida de poder adquisitivo de gran parte de la población; la popularización de nuevas pautas para 
la ciudad entre las que se incluye la sostenibilidad o la expansión de la moda global de la bicicleta, unida al éxito del modelo de implantación, así como su entrada en agenda de diferentes ámbitos de la administración y las políticas públicas. A ellos se suman las constricciones medioambientales y climáticas para cada ciudad, las propias configuraciones del espacio urbano, o el grado de desarrollo anterior de otras culturas ciclistas, además de las culturas ciclistas de transporte. La Tabla 1 resume algunos de estos procesos abiertos en las diferentes ciudades andaluzas, reflejando la estimación cualitativa y cuantitativa que, a partir de nuestro estudio, representa el ciclismo como transporte en cada entorno urbano, los usos ciclistas predominantes, y una estimación de la calidad de las infraestructuras ciclistas a partir de su grado de articulación con los principales nodos de interés para el desplazamiento:

\begin{tabular}{|l|l|l|c|l|}
\hline Ciudad & $\begin{array}{l}\text { Desarrollo del ciclismo } \\
\text { como transporte }\end{array}$ & Usos predominantes & $\begin{array}{l}\text { Kilómetros de carril- } \\
\text { bici construidos }\end{array}$ & $\begin{array}{l}\text { Grado de articulación } \\
\text { con nodos de interés }\end{array}$ \\
\hline Almería & Medio-bajo & Recreativo & 37 & Media \\
\hline Sevilla & Alto & Transporte-recreativo & 180 & Alta \\
\hline Cádiz & Medio-bajo & Recreativo & 15 & Media \\
\hline Córdoba & Medio & Recreativo-transporte & 52 & Media \\
\hline Granada & Medio-bajo & Deporte & 20 & Media \\
\hline Huelva & Medio-bajo & Recreativo-deporte & 19 & Media \\
\hline Jaén & Bajo & Recreativo & 20 & Baja \\
\hline Málaga & Medio & Recreativo & 35 & Media \\
\hline
\end{tabular}

Tabla 1. Desarrollo del ciclismo como transporte, usos predominantes y otros factores asociados a los usos ciclistas Fuente: proyecto CICLA, elaboración propia.
Es preciso advertir que la mayor parte de estas ciudades se encuentran en la actualidad en un proceso de expansión de sus infraestructuras, con una ampliación de kilómetros de carril-bici proyectados que en algunos casos es significativa. Por poner algunos ejemplos, de cumplirse los proyectos de administraciones locales y autonómicas en el corto-medio plazo, Cádiz ampliaría en $21 \mathrm{~km}$ la longitud total de sus vías ciclistas y Huelva duplicaría su situación inicial, alcanzando los 38 kilómetros.

Esta evolución cuantitativa tiene también su correlato en términos cualitativos. Más recientemente, se comprueba la expansión del ciclismo como transporte, tanto por su valoración positiva por la población, como por la dilución de los estereotipos antes referidos, en ciudades como Cádiz, Málaga o Almería, con avances apreciables, aunque menos significativos, en otros territorios. Como hemos apuntado, las constricciones geográficas y ambientales participan también en esta composición, encontrando cierta conexión con la destacada presencia del ciclismo deportivo, y de forma complementaria, con las dificultades del ciclismo utilitario. Sobresalen aquí los casos de Granada y Córdoba, con alta presencia del ciclismo deportivo, y con recurrentes discursos que evidencian las dificultades para moverse en bicicleta para desplazamientos "de transporte" por las zonas más abruptas de la ciudad. En este mismo ámbito se sitúa la estacionalidad que se aprecia en los usos ciclistas en otras ciudades, como Sevilla o Córdoba, durante el caluroso período estival, o en Cádiz, cuando arrecia el potente viento de levante, enemigo del ciclista. 


\section{Percepciones sobre el desarrollo de las infraestructuras ciclistas}

En este proceso de progresiva pero asimétrica normalización el desarrollo de las infraestructuras ciclistas adquiere un alto protagonismo. Este desarrollo está fuertemente vinculado a la construcción de redes de carriles-bici eficientes y articuladas, pero no solo esto. Si afirmamos que los usos de la bicicleta cada vez son más complejos, hemos de pensar en cómo los ciclistas son cada vez más heterogéneos, así como lo son sus necesidades y demandas. En este sentido, al tiempo que se van consolidando los usos, las condiciones, las infraestructuras, las políticas, etc. la presencia de la bici y las peticiones de quienes la utilizan, se han ido complejizando, ampliando y diversificando. En este punto es clave reparar en el elemento central de nuestra reflexión y constatar cómo la demanda de infraestructuras ciclistas en la ciudad se diversifica y se hace más experta. Ya se demandan con mayor conocimiento una serie de infraestructuras, a las demandas de mejor articulación en las vías ciclistas se van sumando las de aparcabicis de calidad que respondan a las necesidades de los ciclistas para un uso continuado:

Entonces, muchas veces lo que te encuentras es que la vía ciclista está identificada, está pintada en el suelo pero es una parte de la calzada (...) por la zona de costa está cubierta, pero cuando llegas aquí al centro ya no hay, no está identificado, no hay zonas de preferencia bici. ¿Qué se hace con la bici cuando se llega aquí? Pues te metes en el tráfico, y yo creo que esto es donde habría de trabajar... (técnico de la administración local, Cádiz).

Los aparcabicis estos de anilla, de espiral, son un desastre, son antiguos, dobla ruedas... y ahora están poniendo, un modelo ese está muy bien, no tan bonito... no es de acero inoxidable... (ciclista, Cádiz).

Se ha avanzado un poco en el tema de los autobuses, donde ya se puede llevar la bici en los autobuses urbanos siempre que sea plegable y siempre que lo permita la cantidad de personas que viajen en ese momento, pero cabría también el fomentar estaciones de bicicletas en alquiler, que favoreciera que las personas pudiéramos ir en bicicleta y a continuación coger el autobús y viceversa (representante de asociación ciclista, Málaga).

En una valoración general, para el caso andaluz, se comprueba que las infraestructuras de la bicicleta son consideradas claramente insuficientes, tanto en lo que respecta a vías segregadas como a aparcamientos o servicios de bici pública. Las redes de vías ciclistas no son consideradas como tales por no cumplir los requisitos de continuidad y conectividad, cuestiones que fundamentan las percepciones sobre su funcionalidad y consecuentemente el uso y el éxito de estas. Se evidencian diversas deficiencias, entre las que destacan la falta de mantenimiento - y su consiguiente mal estado-, el mal diseño de algunos tramos, o simplemente, su ubicación alejada en zonas con poca actividad urbana que, unido a la falta de una correcta señalización que disuada usos indebidos, acaban produciendo una red de baja o nula utilidad, convirtiéndose en ocasiones en origen de conflictos.

Hay algunos casos singulares que evidencian los retos a afrontar en la mejora de la promoción de la bicicleta como medio de transporte. Se comprueba, por ejemplo, en algunos entornos urbanos estudiados 
algunas prácticas recurrentes, como la construcción de infraestructuras ciclistas ubicadas en zonas verdes apartadas o extrarradio, escasamente articuladas entre sí. Muchos de estos carriles bici han sido ubicados a modo de circunvalación de la ciudad y discurren por zonas de los extrarradios, poco atractivas para el paseo. Son las popularmente llamadas "rondas del colesterol", pues dentro de sus funcionalidades fueron pensadas para fomentar el caminar y el pedalear. Desde los colectivos pro-bici, se critica que son escasamente utilizadas y que se trata de intervenciones que no cuestionan el modelo de transporte motorizado dominante, y que por tanto no tienen consecuencias significativas en la modificación de los hábitos de movilidad en la ciudad. Algunos usuarios consultados rechazan su uso porque "no conectan con nada ni llevan a ningún lado", pues transcurren por lugares apartados e inhóspitos. En general, se subraya que el problema de este tipo de intervenciones es su escasa combinación con la construcción de carriles bici dentro del trazado urbano, formando una red articulada y coherente, que conduzca a lugares de interés como centros de trabajo y estudio, nodos de transporte, etc.

\section{Las economías de la bici}

La dimensión socioeconómica es otra de las grandes emergencias de esta proliferación de la bicicleta. La mayor parte de las numerosas iniciativas económicas vinculadas a la bicicleta existentes están surgiendo al hilo de este auge de la bicicleta. En todas las ciudades pueden observarse la emergencia de negocios conectados con la infraestructura hotelera y las necesidades de desplazamientos en bici de los turistas (con casos significados en Sevilla, Córdoba o Málaga), al cicloturismo rural (Córdoba, Málaga y Granada) o la llegada de la turismo de cruceros (Cádiz y Málaga), por poner algunos ejemplos. Mayoritariamente se trata de pequeños negocios, de carácter local o de barrio en los que predomina una verdadera vocación hacia la bicicleta, pero también hacia la mejora de nuestras ciudades. El papel que desempeñan en torno a la puesta en valor de la bicicleta como vehículo, junto a otras particularidades del sector como su distribución geográfica, la progresiva diversificación de productos y servicios, las ventajas del trato personalizado, etc., configuran un panorama de claro potencial de desarrollo. Empresarios y agentes relacionados con el sector de la bicicleta en algunas de las ciudades consultadas (destacando aquí los casos de Sevilla, Málaga y Cádiz, con experiencias significativas en otros entornos) refieren el potencial de este sector para desestacionalizar la actividad turística y para ofrecer la posibilidad de diversificar actividades, aportar por la sostenibilidad ambiental y ampliar las pernoctaciones.

No obstante, no son pocas las limitaciones y dificultades por las que atraviesan buena parte de las iniciativas en este sector. Algunas tienen que ver con los procesos socioculturales de integración de la bicicleta a la movilidad urbana, como la valoración de la propia bicicleta como vehículo, de los oficios a ella vinculados y su relación con los tipos de consumo. Otras cuestiones, como los costes de mantenimiento de la actividad económica responden a aspectos estructurales y a la falta de valoración de un sector que es pieza clave en la transición hacia modelos más sostenibles.

Pero esta expansión de la economía de la bici, que ha ido de la mano del incremento de sus usos urbanos como deportivos, supone, además del aumento en el número de negocios, una más que interesante diver- 
sificación de productos y servicios: mayor variedad en el tipo de bicicletas - de paseo, plegables, fixies, eléctricas, deportivas, BMX, customizadas...-, aparición de empresas dedicadas al turismo en bicicleta, a la bicimensajería, empresas de publicidad y nuevas tecnologías, etc. En la medida en que se asienta el uso de la bicicleta como medio de transporte, proliferan los negocios asociados a esta modalidad, que intentan cubrir sus necesidades, destacando el caso de Sevilla, con un incremento notable en la presencia de talleres y tiendas de repuestos.

\section{Resignificación urbana: sociabilidad, espacios, subculturas}

La presencia de la bicicleta ha despegado multitud de procesos de carácter sociocultural y económico que se insertan en las dinámicas propias de la ciudad. A partir de este complejo mestizaje se han producido cambios en las propias imágenes de las ciudades y resignificaciones sobre la bicicleta y sobre quienes la usan. Por eso, la relevancia que ha adquirido la bicicleta como elemento articulador de sociabilidades no puede pasarse por alto. Sus virtudes para facilitar el encuentro y la participación en los espacios públicos se muestran evidentes.

Se comprueba cómo en torno a la bicicleta se articulan grupos y colectividades y también en torno a ella existen espacios y tiempos que permiten la combinación del ocio, la festividad y la reivindicación: desde las planificadas Fiestas de la Bicicleta (destacan los casos de Sevilla y Córdoba de masiva asistencia) a las bicifestaciones y manifestaciones con la bicicleta como eje central (en Sevilla, Granada, Málaga o Almería), pasando por un sinfín de encuentros formales o informales y reuniones. En muchos clubes de carácter deportivo de todas las ciudades analizadas, sobresale la dimensión lúdico-festiva, con usuarios/as que disfrutan de salidas al campo, o comparten desayunos en bares en la ruta o aperitivos a la llegada. En otras ciudades con culturas ciclistas más desarrolladas, como es el caso de Granada, la mayor proliferación de clubes y asociaciones deportivas también está asociada a este componente lúdico, pero presentan un mayor componente deportivo, en sus connotaciones de entrenamiento, rendimiento y preparación física. En resumen, en la mayor parte de las prácticas ciclistas se evidencia el placer de disfrutar de modo compartido del espacio público, de la ciudad o del medio ambiente urbano. Incluso en los discurso de los ciclistas considerados "de transporte", encontramos referencias al placer de usar la bicicleta para desplazarse al trabajo o a los estudios.

\section{El papel de las políticas públicas}

Finalmente, las potencialidades e implicaciones sociales del ciclismo urbano están fuertemente afectadas por el papel de las políticas públicas y de participación que giran en torno a su proliferación. En ello participan desde el Plan Andaluz de la Bicicleta (2014-2020) a las distintas acciones y políticas locales, pasando por las propias orientaciones de la Dirección General de Tráfico que puedan afectar a la circulación urbana, el efecto en la consolidación de la bicicleta como medio de transporte.

La mayoría de agentes consultados coinciden en la necesidad de que los planeamientos y políticas no generen distorsiones entre unas acciones políticas y otras que puedan comprometer los objetivos de promoción ciclista marcados. De manera concreta vemos cómo el Plan 
Andaluz de la Bicicleta se convirtió en pieza clave para articular esta dimensión sociopolítica de la que venimos hablando; por un lado materializaba la expectativa al tiempo que la desconfianza, y no solo por los logros a los que se pensaba que se podría llegar, sino y sobre todo por la posibilidad de participación que ofrecía a usuarios y demás sectores implicados. Se abría a partir de ello la oportunidad de facilitarles a estos el acceso a la construcción de un modelo de ciudad y unas acciones políticas sobre la base de algo tan cotidiano, cercano y mundano como es utilizar la bicicleta como medio de transporte.

Como reto general, los discursos de distintos agentes implicados en la promoción de la bicicleta refieren que muchas de las planificaciones y normativas proyectadas no se plasman en la realidad o no son llevadas a término. En algunos casos, se constata que los planeamientos urbanísticos no reciben asignación presupuestaria suficiente para su ejecución. En otros casos, se argumenta que no existe una política específica e integrada en una planificación, echándose en falta un organismo de referencia que centralice y dé continuidad a las actuaciones en torno a la bicicleta en cada ciudad. Si estas actuaciones se caracterizan por ser tímidas y discretas, el resultado es cierto estancamiento o ralentización de la promoción del ciclismo urbano que deposita en muchos casos su expansión en el propio impulso que dan los usos y prácticas sociales.

\section{Discusión}

Como hemos visto, existe una tónica generalizada de constatación de deficiencias en las infraestructuras ciclistas, si bien el grado de implementación de infraestructuras ciclistas en ciudades andaluzas es muy diferente, así como las exigencias y propuestas generadas en este sentido. Como en otros muchos ámbitos, el papel de las infraestructuras es fundamental de cara a garantizar el acceso a la población a los colectivos con menos experiencia ciclista o menos aptitudes físicas, pero también para disminuir las tasas de riesgo de la movilidad en bicicleta (Aldred, Woodcock y Goodman, 2016).

Por otra parte, se comprueba que una nueva ciudad se dibuja desde los pedales. Pedalear posibilita entender la ciudad a otra escala, contemplar paisajes diferentes, percibir olores, colores, sonidos y ritmos distintos. El uso de la bicicleta proporciona una gran cercanía con el entorno y unas formas de interacción con la ciudad y con los propios vecinos más estrecha; la ciudad se hace de este modo más habitable, más cercana y segura (Horton y Parkin, 2012). La bicicleta coadyuva al desarrollo de diversas redes de sociabilidad: complicidad entre quienes pedalean a diario y también entre amistades que se forman al calor de grupos de ciclistas deportivos, como hemos visto, ya sean de montaña o de carretera. Otra dimensión observada son las complicidades e identidades que se generan en torno a determinados estilos y prácticas ciclistas: las bicis diferenciadas o customizadas, hechas a medida, y que marcan un sello de diferenciación y reconocimiento mutuo entre aquellos que las llevan o los grupos que se articulan en torno a determinadas prácticas. En suma, todo ello supone evidencias que subrayan los beneficios del ciclismo urbano para la "salud social" de la población (Whitaker, 2005).

En lo relativo al análisis de los usos ciclistas predominantes, se constata la convivencia entre los usos de transporte y de ocio, aunque con claro protagonismo para estos últimos. De cara a procurar mejoras en la movilidad, en la salud de las personas y en el ambiente urbano, la promo- 
ción de la bicicleta como medio de transporte es prioritaria, como confirman otros estudios (Gatersleben y Appleton, 2007; Handy, Van Wee y Kroesen, 2014). Sin embargo, no debe despreciarse el efecto trasvase que se produce desde el ciclismo de ocio y de deporte hacia el medio de transporte. De hecho, sigue siendo la forma mayoritaria de acceso a una cultura ciclista por parte de los más jóvenes (Jordi-Sánchez, 2018).

Uno de los frentes estratégicos de potenciación de la presencia de la bicicleta en la ciudad es el de carácter económico. Entendemos que el uso de la bicicleta presenta un gran potencial para el desarrollo económico, caminando hacia un modelo descentralizado, diverso y basado en pequeñas empresas. Al mismo tiempo, un modelo de movilidad con mayor presencia de la bicicleta encierra, sin duda, un gran potencial sobre el desarrollo de un tejido económico local, favoreciendo el desarrollo del pequeño comercio, entre otras cuestiones. Paralelamente, las empresas del mundo de la bicicleta no solo interesan en su dimensión puramente crematística, sino que también en su dimensión social, pues generan un pequeño tejido empresarial de colaboración, son espacios de sociabilidad para grupos ciclistas y muchos de ellos incorporan diversas actividades y líneas de trabajo dirigida al fomento y difusión de la bicicleta. Mención aparte merece lo que está aconteciendo con relación al uso turístico de las bicicletas, que sin duda abre una oportunidad desde varias perspectivas concurrentes: el cicloturismo se plantea como un sector con un gran potencial en muchos sentidos (Lamont, 2009). El turismo, además, ofrece una cara atractiva de la bici y encierra el potencial de renovar, actualizar y componer una imagen nueva de nuestras ciudades y pueblos, que sean por un lado más atractivas como productos turísticos, y por otro, mejor valoradas por sus moradores/as.

Finalmente, queda patente la necesidad de una mayor claridad y determinación en los posicionamientos desde los órganos de gestión pública con respecto a la promoción ciclista. No es posible apostar por todos los medios de transporte en un espacio finito y que definitivamente está jerarquizado a favor del automóvil. El fomento del uso de la bicicleta debe integrarse en una propuesta más amplia sobre el modelo de movilidad y el espacio urbano, de carácter social, habitable y entendido como un concepto político en el que confluyen una multiplicidad de usos, de miradas y de intersecciones (Delgado y Malet, 2007). Se hacen necesarios espacios de encuentro, de participación, que den cabida a la pluralidad de voces existentes entre los diferentes agentes sociales y desde donde se deben tejer vínculos entre la población local y las administraciones públicas, sobre quienes finalmente recae la toma de decisiones. En nuestro ámbito de estudio andaluz, en el que ha cobrado singular protagonismo las diferentes acogidas locales del $\mathrm{PAB}$, parece especialmente interesante esta dimensión participativa en tanto que permite contemplar y utilizar las particularidades que cada sociedad local ofrece a una planificación general, al tiempo que potenciar ciertas lógicas culturales de funcionamiento sin las cuales es imposible el éxito real de cualquier intervención pública.

\section{Reflexiones para continuar: hacia una enculturación ciclista}

La bicicleta, aquel invento del xix que generó una auténtica revolución entre hombres y mujeres de aquella época, no ha llegado nunca a desaparecer de nuestras vidas; aun así, la sacralidad del automóvil y 
todo el imaginario social asociado a él, provocaron que sus virtudes como medio de transporte quedaran socialmente invisibilizadas. Sin embargo, durante la última década, las bicicletas parecen ir demostrando (o recuperando) su potencial como un vehículo particularmente eficaz en los desplazamientos urbanos y metropolitanos. El desarrollismo de los años sesenta y setenta fue expulsando a las bicicletas de las calles, en paralelo a la expansión del automóvil; su vuelta está siendo lenta, desde hace apenas una década.

Los sistemas de movilidad y transporte han sido aspectos centrales en la configuración de toda ciudad y en sus dinámicas socioeconómicas. Los desplazamientos que hacemos y los medios de transporte que utilizamos, dan cuenta de la organización social, cultural y económica de nuestras sociedades al tiempo que intervienen en las formas de habitar y construir el espacio público. El vehículo privado y todas las infraestructuras asociadas a él han sido pieza clave para facilitar estos procesos que, en definitiva, han ido componiendo las formas de pensar, construir y transitar nuestros entornos.

En los discursos y prácticas relativos a los usos de la bicicleta en la zona de nuestro estudio, hemos constatado que la conformación de una "cultura ciclista" afronta una serie de singularidades y retos. Si conseguimos aislar los usos de "transporte" u "obligados" de aquellos usos más "recreativos" o "deportivos", comprobamos que, pese a los avances, estos últimos aún sobrepasan claramente a los primeros en términos de uso predominante entre la población. Esto se percibe en la forma de circular, o en los discursos y prácticas de los ciclistas, como hemos visto. Y se percibe también en la praxis política: la predominancia de una imagen estereotipada afecta también a un modo de gestión en el que infraestructuras, normativas o iniciativas de promoción identifican ciclista con deportista o paseante optando por la construcción, por ejemplo, de "rondas del colesterol" donde segregar a tales ciclistas, antes que introducirlos en las redes del tráfico en la ciudad a través de vías ciclistas o de zonas de tráfico calmado. Esto se traduce también en la práctica habitual de entender que apoyar la "cultura ciclista" significa poco más que colaborar en la promoción de grandes eventos deportivos ciclistas (Martín y Gálvez, 2016). En los lugares en los que las infraestructuras ciclistas contradicen esta tendencia general, de los que Sevilla es ya un referente, la ruptura de estereotipos y prejuicios avanza lenta pero firmemente. Pero este avance se encuentra con el reto de que su continuidad sea firme y decidida, superando el riesgo de convertirse en una "moda pasajera". Para ello las labores de promoción del uso de la bicicleta son primordiales, pues consolidan, amplían y fortalecen aquello que se ha venido trabajando, fundamentalmente, desde el impulso de las infraestructuras.

Y es aquí donde apunta nuestra principal conclusión y propuesta: en no entender el fomento del uso de la bicicleta per sé, sin un cuestionamiento previo, no ya de las formas de movilidad sino del modelo de ciudad imperante. El fomento del uso de la bicicleta debe integrarse en una propuesta más amplia sobre el espacio urbano, que dé cabida a su capacidad de hacer ciudades más accesibles destacando su potencial para la combinación con otros modos de transporte, lo que aparece como uno de los principales hándicaps a superar, especialmente en los entornos metropolitanos.

La creación de una infraestructura ciclista rara vez es por sí sola garantía de un fomento del número de usuarios si no va acompañada de otras medidas que proporcionen sinergias capaces de fortalecer el fe- 
nómeno ciclista. La existencia de una masa ciclista previa, la presencia e implicación de colectivos y movimientos sociales y el grado de información y sensibilización de la sociedad local pueden llegar a ser tanto o más determinantes que la propia infraestructura en sí. Esta es otra de las grandes conclusiones que además orientan las recomendaciones que se derivan de nuestro estudio. Adquiere aquí un papel fundamental la necesidad de intensificar y diversificar las acciones de promoción, especialmente las dirigidas a la integración de colectivos minoritarios en el transporte ciclista por diversas razones: capacidad física, género o edad, entre otros. Especial relevancia adquiere la necesaria apuesta por la promoción de la bicicleta en la infancia de un modo integral, sistemático y continuado, más allá de acciones puntuales o descoordinadas.

El carácter híbrido y versátil de la bicicleta interviene en la construcción de los nuevos mapas de la ciudad y también en las maneras en las que este vehículo convive con otras formas de locomoción en los diferentes espacios urbanos. En este sentido, en casos como el de Sevilla, con mayor intensificación y desarrollo en los procesos de integración de la bicicleta, podemos hablar de una favorable evolución de estas convivencias, especialmente con los/as viandantes, pues es con quienes se producen mayores interacciones debido al diseño y disposición de las vías ciclistas, cuando estas existen. No obstante, y tomando en cuenta las diferencias entre unas ciudades y otras, aún queda trabajo en aras de una mejor gestión, así como en la generación de consensos, sobre todo en las zonas donde las infraestructuras ciclistas aún no proporcionan al ciclista un lugar propio para circular, y para ser considerado dentro de la movilidad urbana.

Concretamente, nos referimos a las acciones de promoción de la cultura ciclista. En nuestro ámbito, el estado de desarrollo de este tipo de acciones puede considerarse de modo general como embrionario, pues queda aún mucho que hacer en muchos lugares. Existe cierto consenso en los discursos al situar en dos ámbitos fundamentales tales acciones: la educación y la sensibilización, ámbitos separados, pero estrechamente relacionados. Por una parte, la educación se enfocaría desde la educación vial y ambiental, así como el respeto para aprender a convivir con el resto de los modos de transporte y usuarios/as de las vías públicas, pero también se dirigiría a contribuir a aumentar la confianza y el dominio de la bicicleta para una conducción segura en el caso de ciclistas o potenciales usuarios/as de la bicicleta. La sensibilización por su parte se encaminaría a superar las reticencias de carácter cultural y a cuestionar los diferentes estatus sociales asignados a los distintos modos de transporte, así como a promover una toma de conciencia sobre las problemáticas (sociales, económicas, ambientales...) derivadas de nuestro actual modelo de movilidad. Ambos, educación y concienciación, serían ámbitos en los cuales trabajar las ventajas e implicaciones de salud, ambientales y logísticas del uso de la bicicleta.

Es un planteamiento erróneo el situar como público objetivo de estas acciones exclusivamente a los propios ciclistas. Si se trata de romper estereotipos, por ejemplo, habrá que trabajar allá donde predominan, situándose aquí los usuarios de automóviles a la cabeza. Si hay que fortalecer modos de conducción segura, habrá colectivos y tramos de edad en los que dicha necesidad es más palpable: mujeres, niños y personas mayores, etc. No puede generalizarse ni anticiparse cuál deberá ser el objeto de la promoción porque dependerá del contexto social, económico, político, de movilidad, etc. en el que nos encontremos. 
Tampoco puede reducirse a un solo ámbito. Educar y concienciar para evitar la conducción insegura, temeraria o irrespetuosa de algunos ciclistas no puede convertirse en el único, ni el principal objetivo. En todo caso, este complejo proceso de enculturación ciclista tiene una característica fundamental: su dilatación en el tiempo. Comprometerse a cambiar de hábitos, de costumbres, valores y percepciones no es asunto solo de una charla, un cursillo o unos carteles bien colocados.

Finalmente, solo queda reiterar que este tipo de acciones debe establecerse de forma coordinada con el desarrollo de otras de las que venimos hablando, de las que ocupan un lugar central las infraestructuras. Los objetivos de promoción pueden ser contraproducentes si se proponen acciones que solo puedan abordarse en el plano teórico. En otras palabras, sin una red articulada y de calidad de vías ciclistas y sin tráfico calmado en la ciudad, promover la cultura ciclista es predicar en el desierto. En este sentido, la apuesta del PAB de ahondar en el avance de las infraestructuras en entornos en los cuales se duda que la "cultura ciclista" esté mínimamente desarrollada, la entendimos como todo un acierto; los retrocesos o involuciones en el transporte ciclista ante la congelación de dicho Plan, lo ponen de manifiesto.

La integración de la bicicleta en las ciudades andaluzas es un proceso que ya está en marcha y en el que han intervenido multitud de elementos y agentes sociales. El actual contexto socioeconómico, junto con el incremento de ciudadanos/as que han decidido pedalear para desplazarse, se tejen con las resignificaciones que ha experimentado la bicicleta, sus usuarios/as y la ciudad misma. Las implicaciones de este proceso son amplias y apuntan a la emergencia de una cultura ciclista en Andalucía. La orientación y gestión de todo este proceso de cambio irá definiendo los caminos futuros, los pasos a seguir y permitirá o no visualizar y aprovechar los retos y potencialidades que en estos momentos plantean los usos de la bicicleta. Al igual que para muchos de los hombres y mujeres con los que hemos reflexionado y pedaleado durante este tiempo, para nosotros/as, la bicicleta ha llegado para quedarse. 


\section{Referencias bibliográficas}

Aldred, Rachel; Woodcock, James; y Goodman, Anna (2016). Does More Cycling Mean More Diversity in Cycling? Transport Reviews, 36(1), 28-44.

Augé, Marc (1993). Los 'no lugares', espacios del anonimato. Una antropología de la sobremodernidad. Barcelona: Gedisa.

Barrios, Juan Carlos (2012). Ecosistemas Urbanos. Ambienta, 98, 144-154.

Castro, Alberto (2015, 14 de julio). Visión general de la Bicicleta Pública en 2014: resumen de los resultados. Entrada en Observatorio de la Bicicleta Pública en España. Recuperado el 15 de mayo de 2020 de: http:/ / bicicletapublica.es/2015/07/14/resumen-de-los-resultado-de-la-revision-de-2014/.

ConBici (2007). Estudio comparado de la situación de la bicicleta en 30 municipios españoles. Recuperado el 15 de mayo de 2020 de: http:/ / www.conbici.org/ joomla/ciudades/estudiocompleto30ciudades.pdf.

Cox, Peter (Ed.) (2015). Cycling cultures. Chester: University of Chester Press.

Delgado, Manuel; y Malet, Daniel (2007). El espacio público como ideología. Ponencia en Jornadas Marx Siglo XXI, 10 de diciembre, Universidad de la Rioja, Logroño.

De Maio, Paul (2009). Bike-sharing: History, Impacts, Models of Provision, and Future. Journal of Public Transportation, 12, 41-56.

DESA (2011). World Population Prospects: The 2010 Revision. New York: Naciones Unidas

Herrmann, Michael; Guzman, José Miguel; y Schensul, Daniel (2012). Population Matters for Sustainable Development. New York: UNFPA.

Hsieh, Hsiu-Fang; y Shannon, Sarah E. (2005). Three approaches to qualitative content analysis. Qualitative health research, 15(9), 1277-1288. DOI: https:/ / doi.org/10.1177/1049732305276687.

Garrard, Jan; Rissel, Chris; y Bauman, Adrian (2012). Health benefits of cycling. En Pucher John; y Buehler, Ralph (eds.) City cycling. Cambridge: MIT Press.

Gatersleben, Brigitta; y Appleton, Katherine. M. (2007). Contemplating cycling to work: Attitudes and perceptions in different stages of change. Transportation Research Part A: Policy and Practice, 41(4), 302-312. DOI: https://doi.org/10.1016/j. tra.2006.09.002.

Handy, Susan; van Wee, Bert; y Kroesen, Maarten (2014). Promoting cycling for transport: research needs and challenges. Transport Reviews, 34(1), 4-24. DOI: https://doi.org/10.1080/01441647.201 3.860204.

Hernández, M. (Ed.) (2016), Bicitopías: Hacia una antropología de la movilidad urbana. Barcelona, Icaria.
Horton, David; Rosen, Paul; y Cox, Peter (2007) Cycling and Society. England y USA: Ashgate.

Horton, David; y Parkin, John (2012) Conclusion: Toward a revolution in Cycling. En Parkin, John (ed.), Transport and Sustainability, Vol. 1: Cycling and Sustainability (pp. 303-325 ). Bradford: Emerald Insight.

Jordi-Sánchez, Mario (2018). Social perceptions of the promotion of cycling as a mode of transport for children in Andalusia (Spain). Journal of Transport. Geography, 72, 86-93. DOI: https://doi. org/10.1016/j.jtrangeo.2018.08.014.

Junta de Andalucía (2014). Plan Andaluz de la Bicicleta. Recuperado el 1 de marzo de 2020 de: http:/ / www. juntadeandalucia.es/fomentoyvivienda/portalweb/ web/areas/transportes/plan_bici.

Larsen, Jacob; y El-Geneidy, Ahmed M. (2009). Build it, but where? The use of Geographic Information Systems in identifying optima location for new cycling infrastructure. Transportation Research Board 89th Annual Meeting.

Martín, Isabel; y Gálvez, Cristina (2016). Discursos sobre infraestructuras de la bicicleta. En Hernández, Macarena (ed.), Bicitopías. Hacia una antropología de la movilidad urbana (pp. 31-50). Barcelona: Icaria.

Marqués, Ricardo; Hernández-Herrador, Vicente; Calvo-Salazar, Manuel; y García-Cebrián, José Antonio (2015). How infrastructure can promote cycling in cities: Lessons from Seville. Research in Transportation Economics, 53, 31-44.

Parkin, John (ed.) (2012). Transport and Sustainability. Volume 1: Cycling and Sustainability. Bradford: Emerald Insight.

Paterson, Matthew (2007). Automobile Politics: Ecology and Cultural Political Economy. Cambridge: Cambridge University Press.

Pucher, John; y Buehler, Ralph (2012). Demand for Public Transport in Germany and the USA: An Analysis of Rider Characteristics. Transport Reviews, 32(5), 541-567.

Reiter, Karl; y Wrighton, Susanne (2014). Cyclelogistics: Potential to shift goods transport from cars to bicycles in european cities. Recuperado el 15 de mayo de 2020 de: http:/ / cyclelogistics.eu/docs/111/CycleLogistics_Baseline_Study_external.pdf.

Del Río, Ángel; y Coca, Agustín (2016). El Plan Andaluz de la Bicicleta y los foros de participación. En Hernández, Macarena (ed.), Bicitopías. Hacia una antropología de la movilidad urbana (pp. 53-70). Barcelona, Icaria.

Rueda, Salvador (1996). La ciudad compacta y diversa frente a la conurbación difusa. La construcción de la ciudad sostenible. Primer catálogo español de buenas prác- 
ticas. Madrid: Ministerio de Obras Públicas, Transportes y Medio Ambiente.

UNFPA (2007). State of World Population 2007: Unleashing the Potential of Urban Growth. New York. United Nations Population Fund. Recuperado el 15 de mayo de 2020 de: http:/ / www.unfpa.org/swp/2007.

UNFPA; y Crossette, Barbara (2011). Estado de la población mundial 2011: 7 mil millones de personas, su mundo sus posibilidades. New York: Fondo de población de Naciones Unidas.

Urry, John. (2007). Mobilities. Cambridge: Polity Press.
Willis, Devon Paige; Manaugh, Kevin; y El-Geneidy, Ahmed (2015). Cycling Under Influence: Summarizing the Influence of Perceptions, Attitudes, Habits, and Social Environments on Cycling for Transportation. International Journal of Sustainable Transportation, 9(8), 565-579, DOI: https://doi.org $/ 10.1080 / 15568318.2013 .827285$.

Whitaker Elizabeth, D. (2005). The bicycle makes the eyes smile: Exercise, aging, and psychophysical wellbeing in older Italian cyclists. Medical Anthropology, 24(1), 1-43. DOI: https:/ / doi. org/10.1080/01459740590905633.

Hernández-Ramírez, Macarena y Jordi Sánchez, Mario (2020). Entre infraestructuras y culturas. Discursos y prácticas en torno a la movilidad urbana en Andalucía. Hábitat y Sociedad, 13, 11-28. $<$ http://dx.doi.org/10.12795/HabitatySociedad.2020.i13.02> 